\title{
Suicide rates in people of South Asian origin in England and Wales: 1993-2003
}

\author{
Kwame McKenzie, Kamaldeep Bhui, Kiran Nanchahal and Bob Blizard
}

\section{Background}

Low rates of suicide in older men and high rates in young women have been reported in the South Asian diaspora worldwide. Calculating such suicide rates in the UK is difficult because ethnicity is not recorded on death certificates.

\section{Aims \\ To calculate the South Asian origin population suicide rates and to assess changes over time using new technology.}

\section{Method}

Suicide rates in England and Wales were calculated using the South Asian Name and Group Recognition Algorithm (SANGRA) computer software.

\section{Results}

The age-standardised suicide rate for men of South Asian origin was lower than other men in England and Wales, and the rate for women of South Asian origin was marginally raised. In aggregated data for 1999-2003 the age-specific suicide rate in young women of South Asian origin was lower than that for women in England and Wales. The suicide rate in those over 65 years was double that of England and Wales.

\section{Conclusions}

Older, rather than younger, women of South Asian origin seem to be an at-risk group. Further research should investigate the reasons for these changes and whether these patterns are true for all South Asian origin groups.

\section{Declaration of interest}

K.N. developed the SANGRA software.
Low rates of suicide in older men of the South Asian diaspora and high rates in young women have been reported across the world. ${ }^{1}$ Concern about suicide rates in women of South Asian origin in England and Wales has led to consideration of the need for specific suicide prevention initiatives. ${ }^{2-7}$ Prevention strategies require accurate contemporary information. The calculation of South Asian suicide rates has been hampered by the fact that place of birth, not ethnic group, is recorded on UK death certificates. Using place of birth as a proxy for ethnicity can lead to misclassification, especially as $50 \%$ of people of South Asian origin in England and Wales were born in the UK. ${ }^{8,9}$ A technological advance may help to bridge this impasse. Reliable software has been launched which identifies people of South Asian origin from databases by using their names. ${ }^{10}$ We used this software to calculate the rates of suicide in people of South Asian origin in England and Wales between 1993 and 2003, and to investigate whether there had been any changes over time.

\section{Method}

\section{Name recognition software}

The South Asian Name and Group Recognition Algorithm (SANGRA) identifies South Asian individuals in data-sets by matching their names to the names in its directory. ${ }^{10}$ SANGRA has been validated using health-related electronic data containing names and self-assigned ethnicity, and has been used in a number of other epidemiological studies. ${ }^{10-12}$ Its reported sensitivity is 89 $96 \%$ and specificity $94-98 \%$ for self-assigned ethnicity census categories 'Asian Bangladeshi', 'Asian Indian' or 'Asian Pakistani'.

\section{Suicide data}

We obtained data from the Office for National Statistics on all deaths in England and Wales between 1993 and 2003 that received a verdict of suicide or an open verdict at coroner's inquest. This was the period for which electronic data were available.
Specifically, ICD-9 codes E950-959 and open verdicts E980-989 (excluding pending verdicts E988.8) and ICD-10 X60-84, Y1034 (excluding Y33.9) $)^{13,14}$

\section{Population data}

Population data for England and Wales from the 1991 and 2001 censuses were provided by the Office for National Statistics. For this analysis, the South Asian origin population included those who assigned themselves to 1991 census categories 'Asian: Bangladeshi, Indian, Pakistani' and 2001 census categories 'Asian or Asian British: Bangladeshi, Indian, Pakistani'. In the 2001 census another ethnicity variable - 'Mixed Asian and White' was added. People who assigned themselves to this group were included in the analysis because they could be identified by SANGRA if any of their names were of South Asian origin. The 'Other Asian' group was not included because the majority of this group are of Middle Eastern or Sri Lankan origin.

The denominators for different age groups and for the years 1993-2003 inclusive were estimated using data from the 1991 and 2001 census. Population projections were derived by taking the difference between the number of people in the 1991 and 2001 census in each ethnic group, and adding a tenth of this difference to the population size in each category in each year starting from 1992 and progressing to 2003.

\section{Analysis}

Suicide rates per 100000 person-years were calculated for the whole study period 1993-2003 and for the two periods 1993-1998 and 1999-2003. We analysed these two groups of years because there would have been low numbers of suicides and unstable estimates if gender and age-group comparisons were made on a year-by-year basis. Age-standardised suicide rates were calculated for the South Asian origin population and for both populations of the two periods. The direct standardisation method was used. The population structure used for age standardisation was the sum of the yearly 
population for England and Wales from 1993 to 2003. Age- and gender-specific mortality rates were calculated for 10-year age bands starting at age 15 years for the whole period under study and for two periods 1993-1998 and 1999-2003.

A sensitivity analysis was conducted using published SANGRA sensitivity data. ${ }^{10}$ SANGRA has a sensitivity of $89-96 \%$ (i.e. the range of false negatives is $4-11 \%)$. We took the worst-case scenario and re-ran the analyses with the South Asian origin numerators inflated by $11 \%$.

\section{Results}

There were 54745 suicides in England and Wales between 19932003 inclusive.

A total of 1438 suicides were assigned to the South Asian origin group by SANGRA: 1012 male and 426 female.

\section{Suicide rates using aggregated data for 1993-2003}

The suicide mortality rate for men in England and Wales was 18.68 per 100000 person-years and the age-standardised rate for men of South Asian origin was 13.36. The age-standardised mortality rate for women of South Asian origin was marginally higher than the rate of England and Wales: 6.25 and 5.79 respectively.

\section{Changes in suicide rates between 1993-1998 and 1999-2003}

Aggregated age-standardised and age-specific suicide rates for 1993-1998 and 1999-2003 are shown in Table 1 and Table 2.

Age-standardised suicide rates for men of South Asian origin were lower than the rate for England and Wales for both the 19931998 and 1999-2003 groups. In both groups the suicide rates were lower in 1999-2003 than in 1993-1998.

Age-specific suicide rates in men of South Asian origin were lower than those for England and Wales for all but one of the age groups in 1993-1998 and in all age groups in 1999-2003.
Age-standardised suicide rates in women of South Asian origin were slightly higher than those of England and Wales for both the 1993-1998 and 1999-2003 groups. However, the difference was smaller in 1999-2003 than in 1993-1998. In both groups the standardised suicide rates were lower in 1999-2003 than in 1993-1998.

The elevated age-standardised suicide rate for women of South Asian origin in 1993-1998 was mainly due to high relative rates in the under- 45 age groups, though there were also high relative rates in groups aged over 65 years. However, the elevated age-standardised suicide rate for women of South Asian origin in 1999-2003 was due to high relative rates only in those over 65 . The suicide rate was not elevated for young women of South Asian origin in the 1999-2003 data-set. The age-specific suicide rates were lower in 1999-2003 than in 1993-998 for all age groups of women of South Asian origin under 55 but were higher for all age groups 55 and over.

\section{Sensitivity analyses}

We recalculated the suicide rates allowing for a worst-case scenario of $11 \%$ misclassification, which is the lowest published sensitivity for SANGRA. We inflated the South Asian origin suicide numerators in analyses by $11 \%$. This did not change the findings overall. The differences between age-standardised rates in men of South Asian origin and those of men in England and Wales diminished, and the difference between women of South Asian origin and women in England and Wales increased slightly. The results of comparative analyses for 1993-1998 and 1999-2003 were essentially unchanged.

\section{Discussion}

Our main findings are that men of South Asian origin in England and Wales have a relatively low age-standardised suicide rate and women of South Asian origin have marginally raised suicide rates.

\begin{tabular}{|c|c|c|c|c|}
\hline \multirow[b]{2}{*}{ Age range, years } & \multicolumn{2}{|c|}{ 1993-1998 } & \multicolumn{2}{|c|}{ 1999-2003 } \\
\hline & England \& Wales & South Asian & England \& Wales & South Asian \\
\hline \multicolumn{5}{|l|}{ Male } \\
\hline $15-24$ & 15.84 & 14.19 & 12.45 & 6.77 \\
\hline $25-34$ & 25.98 & 16.03 & 23.25 & 15.99 \\
\hline $35-44$ & 20.74 & 16.61 & 21 & 14.89 \\
\hline $45-54$ & 20.24 & 10.63 & 18.97 & 13.69 \\
\hline $55-64$ & 14.96 & 13.37 & 14.89 & 12.02 \\
\hline $65-74$ & 13.57 & 10.13 & 12.41 & 8.16 \\
\hline over 75 & 20.09 & 23.28 & 17.32 & 12.85 \\
\hline \multicolumn{5}{|l|}{ Female } \\
\hline $15-24$ & 3.45 & 5.89 & 3.37 & 2.67 \\
\hline $25-34$ & 5.65 & 7.89 & 5.36 & 5.34 \\
\hline $35-44$ & 6.21 & 7.4 & 6.11 & 3.95 \\
\hline $45-54$ & 6.86 & 5.65 & 6.47 & 4.56 \\
\hline $55-64$ & 5.98 & 4.17 & 5.8 & 4.85 \\
\hline $65-74$ & 6.67 & 8.87 & 5.29 & 12.51 \\
\hline over 75 & 7.88 & 8.81 & 6.5 & 10.89 \\
\hline
\end{tabular}

\begin{tabular}{|c|c|c|c|c|}
\hline & \multicolumn{2}{|c|}{ 1993-1998 } & \multicolumn{2}{|c|}{ 1998-2003 } \\
\hline & England \& Wales & South Asian & England \& Wales & South Asian \\
\hline Male all ages & 19.29 & 14.50 & 17.77 & 12.38 \\
\hline Female all ages & 6.01 & 6.91 & 5.54 & 5.95 \\
\hline
\end{tabular}


The suicide rates for people of South Asian origin in England and Wales decreased between 1993-1998 and 1999-2003 but for older women the rates increased. In the 1999-2003 data-set, young women of South Asian origin were not at increased risk of suicide.

The results of this study are similar to those of previous research with regard to men of South Asian origin, but are different for women of South Asian origin. ${ }^{2-5,12}$

\section{Younger women}

Studies using place of birth as a proxy variable have reported high standardised mortality ratios for younger ( $<35$ year old) women of South Asian origin. ${ }^{3,5}$ A study using manual name recognition agreed, and identified an $81 \%$ increased suicide rate in women of South Asian origin aged 15-24 years compared with similarly aged women in England and Wales. ${ }^{2}$ A local study which perused coroners' records to determine ethnic group confirmed a near doubling in the risk of suicide in women of South Asian origin under 45 years compared with a White comparison group. ${ }^{15}$

We found only a modestly elevated suicide rate in women of South Asian origin under 35 years of age. Contrary to the previous literature, in more recent years young women of South Asian origin were not at increased risk of suicide. Our findings reflect a change in suicide rates between previous studies undertaken on data from 1970-1990 and our study using more recent data.

There are a number of possible factors that could contribute to a fall in the suicide rate in young women of South Asian origin. These may include the changing demography of the South Asian population in the UK and changes in the amount of stress or the way it is managed in the South Asian population.

\section{Demographic change}

Our South Asian origin group is composed of people of Bangladeshi, Pakistani, Indian and mixed origins. Our findings could reflect differences in the composition of the South Asian origin population over time. The Pakistani and Bangladeshi origin populations are younger than the Indian population. ${ }^{9}$ Their proportion in the younger population at risk increased over the study period while the proportion of Indian South Asians decreased from $59 \%$ to $41 \%$.

Suicide is complex and a number of factors across a life-course influence risk. ${ }^{16}$ Socio-economic and sociocultural factors as well as stress of migration, acculturation and clashes between traditional South Asian cultures and host cultures have been cited as possible risk factors. ${ }^{17}$ These vary by group. For instance, poverty and unemployment levels are high in the Bangladeshi community, while educational attainment is high in those of Indian origin but lower than average in those of Pakistani and Bangladeshi origin. ${ }^{18,19}$ However, we need to be careful in assuming that standard risk factors for suicide act in the same way in different cultural groups. For instance, Raleigh et al found that the pattern of association between suicide and social class was different to that of the general population: $13.8 \%$ of suicides in women of South Asian origin occurred in social class 1 compared with $4.9 \%$ in the general population. ${ }^{2}$

Mental illness is a risk factor for suicide. The prevalence of all types of ICD-10 disorder is least common in the Bangladeshi group, despite their low socio-economic status. Depressive episodes and anxiety disorders are most common among Indian and Pakistani women. ${ }^{20}$

Different religious groups also have different rates of suicide. The Pakistani and Bangladeshi groups are over 90\% Muslim, a religion which generally prohibits suicide, while the Indian group is $75 \%$ Hindu or Sikh. ${ }^{9}$
Because of religious, socio-economic and sociocultural factors, different South Asian origin subgroups may have different risk factors for suicide. As the composition of the South Asian origin population varies so may the rates of suicide. We are unable with the data we have available to investigate which factors linked to the changing composition of the population of South Asian origin are important in the decrease in suicide rates in young women of South Asian origin.

\section{Older women}

All previous studies report rates of suicide for older women of South Asian origin that are similar to or lower than England and Wales, or White comparison groups. ${ }^{2,4,5,15}$ Our study reports a marked increase in suicide rates particularly in people aged over 65 years.

Older groups remain predominantly of Indian origin so changes are unlikely to reflect changes in the composition of the South Asian origin population. The long-term impact of social risk factors, migration and acculturation may be important but it may also be that bereavement and long-term illness are an issue. The life expectancy of men of South Asian origin is lower than that for England and Wales, leaving an increasing number of bereaved older women of South Asian origin. Older women of South Asian origin are also more likely to suffer from a limiting long-term illness. ${ }^{21}$ Both bereavement and long-term illness are known risk factors for depression and suicide.

However, though it may be that the possible differential rate of suicide is due to known risk factors, it is perhaps useful to note that there is little evidence that these risk factors are crossculturally applicable in the UK.

\section{Study limitations}

Major methodological considerations are the accuracy of the SANGRA program, the accuracy of the denominator and the inability of this study to comment on sub-groups within the South Asian population.

\section{Numerator problems}

It is unlikely that SANGRA's performance on the suicide data differed from its performance on other data-sets ${ }^{10-12}$ However, it is possible that it is less specific or sensitive on more recent samples because of secular trends such as intermarriage or a preference for European names which would decrease the proportion of people of South Asian origin with traditional names. This could lead to under-ascertainment and a decreased suicide rate. Against this is the fact that SANGRA was validated using real data which would have reflected these problems and the fact that it uses all names to decide whether a respondent is of South Asian origin. ${ }^{10}$

\section{Denominator problems}

The denominator population is a projection based on the 1991 and the 2001 census. The largest waves of migration of those of Indian, Pakistani and Bangladeshi origin were between the 1950s and 1980s. ${ }^{9}$ There have been low levels of primary immigration since then. We assumed a liner increase in population in line with Office for National Statistics' experimental population projections from 2001 to $2003 .{ }^{22}$ If the increase were not linear, this would lead to error.

\section{Fine-grained analyses of different ethnic groups}

SANGRA does not give information on place of origin of names and so we were unable to disaggregate the South Asian 
population. Given the diverse nature of the South Asian population we are aware of the need for more fine-tuned information.

\section{Implications}

We believe that this study offers the most accurate contemporary assessment of suicide rates in the South Asian population of England and Wales to date because it assesses the rate of the whole population of people with origins in South Asia rather than just those born in South Asia. The increasing suicide rate in older women of South Asian origin is a matter of concern that will need further research. This group could be a target for a prevention strategy. There is much research to be done on this subject. Investigation of sociocultural factors involved in the changing suicide rates could offer useful information on which to base strategies to decrease the rates of suicide found in other South Asian origin populations around the world. Further research could investigate whether there are changes in all South Asian origin groups or whether specific sub-populations have different risks.

Kwame McKenzie, BM, MRCPsych, Centre for Addictions and Mental Health, University of Toronto, Canada, and University of Central Lancashire, UK; Kamaldeep Bhui, MD, FRCPsych, DPClinPsych, Centre for Psychiatry, Barts \& The London Medical School; Kiran Nanchahal, MSc, London School of Hygiene and Tropical Medicine; Bob Blizard, MSc, Department of Mental Health Sciences, University College London, UK

Correspondence: Kwame McKenzie, Social Equity and Health Research, Centre for Addictions and Mental Health, Suite 300, 455 Spadina Ave, Toronto, Ontario, M5S 2G8, Canada. Email: kwame_mckenzie@camh.net

First received 4 Jul 2007, final revision 14 May 2008, accepted 18 Jun 2008

\section{Acknowledgements}

We acknowledge the advice of the steering group chaired by Professor David Gunnell. We also thank Professor Clair Chilvers who suggested this analysis.

\section{References}

1 Patel SP, Gaw AC. Suicide among immigrants from the Indian subcontinent: a review. Psychiatr Serv 1996; 47: 517-21.

2 Raleigh VS, Bulusu L, Balarajan R. Suicides among immigrants from the Indian subcontinent. Br J Psychiatry 1990; 156: 46-50.

3 Raleigh VS, Balarajan R. Suicide levels and trends among immigrants in England and Wales. Health Trends 1992; 24: 91-4.
4 Raleigh VS, Balarajan R. Suicide and self-burning among Indians and West Indians in England and Wales. Br J Psychiatry 1992; 161: 365-8.

5 Raleigh VS. Suicide patterns and trends in people in Indian Subcontinent and Caribbean origin in England \& Wales. Ethn Health 1996; 1: 55-63.

6 Department of Health. A National Suicide Prevention Strategy for England. TSO (The Stationery Office), 2002.

7 Department of Health. Delivering Race Equality in Mental Health Care: A Summary. TSO (The Stationery Office), 2005.

8 Office of Population Censuses and Surveys and General Register Office for Scotland. 1991 Census Ethnic Group and Country of Birth in Great Britain. HMSO, 1993.

9 Commission for Racial Equality. A guide to ethnic groups in Britain. Commission for Racial Equality (http://83.137.212.42/sitearchive/cre/ diversity/ethnicity/index.html).

10 Nanchahal K, Mangtani P, Alston M, dos Santos Silva I. Development and validation of a computerised South Asain Names and Recognition Algorithm (SANGRA) for use in British health-related studies. J Public Health Med 2001; 23: 278-85.

11 Farooq S, Coleman M. Breast cancer survival in South Asian women in England and Wales. J Epidemiol Community Health 2005; 59: 402-6.

12 Feltbower RG, Bodansky HJ, McKinney PA, Houghton J, Stephenson CR, Haigh D. Trends in the incidence of type 1 diabetes in South Asians and other children in Bradford, UK. Diabetic Med 2002; 19: 162-6.

13 World Health Organization. International Classification of Diseases and Related Health Problems (10th revision) (ICD-10). WHO, 1992.

14 World Health Organization. Manual of the International Statistical Classification of Diseases, Injuries and Causes of Death (9th revision) (ICD-9). WHO, 1977.

15 Neeleman J, Mak V, Wessely S. Suicide by age, ethnic group, coroners' verdicts and country of birth. A three-year survey in inner London. Br J Psychiatry 1997; 171: 463-7.

16 Gunnell $D$, Lewis G. Studying suicide from the life course perspective: implications for prevention. Br J Psychiatry 2005; 187: 206-8.

17 McKenzie K, Serfaty M, Crawford M. Suicide in ethnic minority groups. Br J Psychiatry 2003; 183: 100-1.

18 Office for National Statistics. Ethnicity: education http: www.statistics.gov.uk/CCI/nugget.asp?ID=268\&Pos=3\&ColRank=2\&Rank=1000 accessed May 2007.

19 office for National Statistics. Ethnicity: labour market. TSO (The Stationery Office), 2002 (http://www.statistics.gov.uk/CCI/ nugget.asp?ID=271\&PoS=4\&ColRank=2\&Rank=1000)

20 Weich S, McManus S. Common mental disorders In Ethnic Minority Psychiatric Rates in the Community (eds K Sproston, J Nazroo). TSO (The Stationery Office), 2002.

21 Evandrou N. Health and well being. In Focus on Older People (eds A Soule, P Babb, N Evandrou, S Balchin, L Zealey): 39-49. Office for National Statistics, 2005.

22 Office For National Statistics. Population estimates by ethnic group 20012005 (experimental). TSO (The Stationery Office), 2007 (http:// www.statistics.gov.uk/statbase/Product.asp?vlnk=14238). 